Coral Reefs

December 2017, Volume 36 Issue 4 Pages 1263-1268

http://dx.doi.org/10.1007/s00338-017-1621-6

http://archimer.ifremer.fr/doc/00412/52389/

(c) Springer-Verlag GmbH Germany 2017

\title{
Implication of the host TGF beta pathway in the onset of symbiosis between larvae of the coral Fungia scutaria and the dinoflagellate Symbiodinium sp (clade C1f)
}

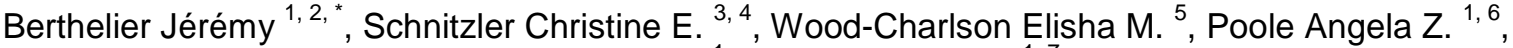 \\ Weis Virginia M. ${ }^{1}$, Detournay Olivier ${ }^{1,7}$
}

${ }^{1}$ Oregon State Univ, Dept Integrat Biol, Corvallis, OR 97331 USA.

2 IFREMER, Physiol \& Biotechnol Algae Lab, F-44311 Nantes, France.

${ }^{3}$ Univ Florida, Whitney Lab Marine Biosci, St Augustine, FL USA.

${ }^{4}$ Univ Florida, Dept Biol, Gainesville, FL USA.

${ }^{5}$ Univ Hawaii, Ctr Microbial Oceanog, Manoa, HI USA.

${ }^{6}$ Western Oregon Univ, Dept Biol, Monmouth, OR USA.

${ }^{7}$ Planktovie Sas, F-13190 Allauch, France.

* Corresponding author : Jérémy Berthelier, email address : berthelier.j@laposte.net

\begin{abstract}
:
Dinoflagellate-cnidarian associations form both the trophic and structural foundation of coral-reef ecosystems. Previous studies have highlighted the role of host innate immunity in regulation of these partnerships. This study reveals the presence of a transforming growth factor beta (TGF $\beta$ ) in the coral Fungia scutaria that clusters with TGF $\beta$ sensu stricto (ss) from other animals. In functional studies of $F$. scutaria larvae, we show that (1) TGF $\beta$ ss mRNA is expressed during early stages of development prior to the onset of symbiosis; (2) apparent interference of the TGF $\beta$ pathway impairs the onset of symbiosis; and (3) this effect is associated with an increase of cytotoxic nitric oxide secretion, an immune response. This work highlights the importance of the TGF $\beta$ pathway in early life-history stages of corals by suggesting that its inhibition impacts the onset of symbiosis.
\end{abstract}

Keywords : Transforming growth factor beta, Cnidarian, Coral bleaching, Dinoflagellate, Symbiodinium, Symbiosis 


\section{Introduction}

Many cnidarians, including corals and sea anemones, engage in an endosymbiosis with photosynthetic dinoflagellates in the genus Symbiodinium. This partnership is based on nutritional exchange where symbionts donate large amounts of reduced organic carbon to their hosts (Muscatine et al. 1984). In return, the hosts provide shelter and inorganic nutrients to the symbionts (Yellowlees et al. 2008). These associations are of major significance because corals form the trophic and structural foundation of coral reefs. Coral-reef ecosystems are considered at risk globally, due to the effects of climate change and other anthropogenic impacts. For example, elevated temperature causes coral bleaching, a symbiosis dysfunction that leads to coral death and reef destruction (Douglas 2003). Worldwide mass bleaching events are increasing in frequency causing large-scale loss of reefs over vast geographic scales (Ainsworth et al. 2016; Normile 2016; Hughes et al. 2017).

Under stable conditions, Symbiodinium sp. resides within host gastrodermal cells of corals, inside symbiosomes of phagosomal origin (Davy et al. 2012). The onset of symbiosis through phagocytosis is a selective process leading to the acceptance of homologous algae and destruction of heterologous algal types (Rodriguez-Lanetty et al. 2004). This mechanism of metazoan innate immune selection is common in invertebrate symbioses and functions to both eliminate negative invaders and promote beneficial partners (McFall-Ngai 2008). In addition to phagocytic selection, basal metazoans have numerous diverse and complex immune repertoires with homology to well-described vertebrate pathways (Miller et al. 2007). In some cases, these repertoires expand beyond those found in vertebrates (Messier-Solek et al. 2010; Buckley and Rast 2012; Hamada et al. 2013). Host innate immunity is now believed to play a central role in the establishment, maintenance, and breakdown of cnidarian-dinoflagellate symbioses (Fuess et 
al. 2016), including symbiosis dysfunction that leads to coral bleaching (Weis 2008).

Transforming growth factor beta (TGF $\beta$ ) members comprise a large superfamily of cytokines with diverse signaling functions, ranging from developmental programming to tissue homeostasis and immunity (Massague 1998). TGF $\beta$ sensu stricto (ss) plays a role in promoting immune tolerance in vertebrates (Bogdan and Nathan 1993; Ruscetti et al. 1993). Homologs to TGF $\beta$ ss have now been identified in basal metazoans including ctenophores (Pang et al. 2011), sponges (Srivastava et al. 2010), and cnidarians (Detournay et al. 2012). In previous work, we explored the role of TGF $\beta$ in the symbiosis between the sea anemone Aiptasia pallida and Symbiodinium minutum (clade B1), a model system for the study of coral symbiosis. We found that the inhibition of TGF $\beta$ with anti-human TGF $\beta$ resulted in (1) immune stimulation, indicated by elevated levels of cytotoxic nitric oxide (NO); (2) a failure of S. minutum to successfully colonize aposymbiotic animals; and (3) a reduction in the bleaching response in heat-stressed animals with addition of exogenous TGF $\beta$, suggesting that tolerogenic TGF $\beta$ attenuated an immune response that contributes to bleaching (Detournay et al. 2012).

In the present study, we examined the role of TGF $\beta$ during the onset of symbiosis in larvae of the coral Fungia scutaria. While our previous work was performed during recolonization of an adult host rendered aposymbiotic by temperature stress, this study focused on onset of symbiosis in naturally occurring aposymbiotic coral larvae that acquire symbionts from the water column after development of a mouth (Schwarz et al. 1999). We characterized TGF $\beta$ ss in the transcriptome of $F$. scutaria and examined its expression in aposymbiotic larvae. We hypothesized that TGF $\beta$ contributes to an overall immune response that promotes tolerance of colonizing symbionts. We examined the effect of TGF $\beta$ inhibition on symbiont colonization success and on the strength of the larval host immune response after symbiont colonization. 


\section{Materials and methods}

\section{Identification of a TGF $\beta$ pathway component homolog from $F$. scutaria}

The putative $F$. scutaria TGF $\beta$ ss (FsTGF $\beta$ ss) sequence was retrieved using the keyword "TGF beta" from the F. scutaria transcriptome available on the Meyer laboratory website (http://ib.oregonstate.edu/ meyere/DB/Fscu/search.php; sequenceID: comp38935_c0_seq1) (Kitchen et al. 2015). The identification method and phylogenetic analysis of the FsTGF $\beta$ ss are described in Electronic Supplementary Material (ESM) Method S1.

\section{Inhibition of the TGF $\beta$ in larvae by incubation in anti-human TGF $\beta$}

To explore a role for TGF $\beta$ in onset of symbiosis, prior to inoculation with symbionts, larvae were pre-treated in anti-human TGF $\beta$ to putatively block coral TGF $\beta$. Larvae (90 $\mathrm{mL}, 1000$ larvae $\mathrm{mL}^{-1}$ ) were treated for $4 \mathrm{~h}$ with indicated concentrations of rabbit IgG-purified anti-TGF $\beta$ (anti-TGF $\beta$; cat\#T-9429, Sigma, St. Louis, MO, USA), or an IgG isotype control (purified IgG from non-immunized rabbit; cat\# 31235, Thermo Fisher, Rockford, IL, USA). Antibodies were suspended in filtered seawater (FSW, $0.22 \mu \mathrm{m}$ ) at a concentration of $1 \mathrm{mg} \mathrm{mL}^{-1}$ according to the manufacturer's recommendations. Treatment concentrations of anti-TGF $\beta$ were $0,0.01,0.1,1.0$ and $2.5 \mu \mathrm{g} \mathrm{mL}^{-1}$. Isotype $\mathrm{IgG}$ was added to each treatment such that there was a final concentration of IgG of $2.5 \mu \mathrm{g} \mathrm{mL}^{-1}$ in all treatments (ESM Table S1). Each experiment also included a no-treatment control (NTC). Following exposure to antibodies, larvae were rinsed and suspended in FSW before quantification of colonization success (ESM Method S2) and/or measurement of NO production (ESM Method S3). 


\section{RNA extraction and cDNA synthesis and quantitative PCR (qPCR)}

Gene expression experiments of TGF $\beta$ coding gene and PABP housekeeping gene were performed on aposymbiotic larvae from the 2014 spawning after development of a mouth ( 3 d). RNA extraction and cDNA synthesis were performed as described previously (Schnitzler and Weis 2010). qPCR was performed with the same concentration of cDNA from 3-d postfertilization larvae ( $\mathrm{t}=0 \mathrm{~h}$ is $1800 \mathrm{hrs})$ and those collected 6,12 and $24 \mathrm{~h}$ later. Larvae were maintained at $26{ }^{\circ} \mathrm{C}$ in a photo-incubator throughout a light/dark cycle (1800-0300 hrs at irradiance level of $100 \mu \mathrm{mol}$ photons $\mathrm{m}^{-2} \mathrm{~s}^{-1} ; 0300-0900 \mathrm{hrs}$ with light off ; 0900-1800 hrs at irradiance level of $50 \mu \mathrm{mol}$ photons $\mathrm{m}^{-2} \mathrm{~s}^{-1}$ ). Thus, the light was on at $\mathrm{t}=0$ and $\mathrm{t}=6 \mathrm{~h}$. Then, the sampling was performed with light off at $\mathrm{t}=12 \mathrm{~h}$ (using a red-light head torch). Finally, the light was on at $t=24 \mathrm{~h}$. Further details on $\mathrm{qPCR}$ method and analyses are in ESM Method S4 and ESM Fig. S1.

\section{Results and discussion}

The FsTGF $\beta$ ss sequence was submitted to NCBI-BLASTx and resulted in a top hit with a TGF $\beta$ sequence from $A$. pallida $\left(\mathrm{KXJ} 22261.1\right.$, e-value $\left.=10^{-71}\right)$. The mature FsTGF $\beta$ ss shares $64 \%$ amino acid identity with the mature TGF $\beta$ ss of $A$. pallida obtained previously (Detournay et al. 2012; AGE84010.1). Multiple alignment between the mature FsTGF $\beta$ ss and mature TGF $\beta$ ss sequences from other organisms, including human, indicated the presence of the nine conserved cysteine residues characteristic of TGF $\beta$ ss (ESM Fig. S2) (Herpin et al. 2005). Amino acid identity of the mature FsTGF $\beta$ ss with human TGF $\beta$ ss 1, 2 and 3 averaged $50 \%$. Moreover, identification of FsTGF $\beta$ ss confirmed a pre-pro-protein structure and the presence of the RXXR cleavage site (ESM Fig. S3). 
Phylogenetic analysis of mature sequences of TGF $\beta$ homologs from various organisms is displayed in Fig. 1. The TGF $\beta$-like group includes TGF $\beta$ ss, activins/inhibins, myostatins, and lefty subgroups. BMP-like ligands branch ladder-like from the TGF $\beta$-like group and include nodal, BMP3, ADMP, Dpp/BMP2/4, Vg1, BMP5-8 and GDF subgroups. With strong support, FsTGF $\beta$ ss groups with other TGF $\beta$ ss sequences, close to $A$. pallida, and between chordate sequences from Branchiostoma floridae and Ciona intestinalis and two ctenophore (Mnemiopsis leidyi) TGF $\beta$ ss sequences (Fig. 1). To our knowledge, this work and our previous study (Detournay et al. 2012) are the only studies that identify TGF $\beta$ ss in cnidarians. However, previous genomic and transcriptomic studies found indications of the existence of TGF $\beta$-like group members in corals (Samuel et al. 2001; Miller et al. 2007; Shinzato et al. 2011; KarakoLampert et al. 2014).

Expression of FsTGF $\beta$ ss in aposymbiotic larvae $3 \mathrm{~d}$ post-fertilization was detectable in all samples and changed through the day. Expression of FsTGF $\beta$ ss at $0 \mathrm{~h}$ (1800 hrs, light on) was high and significantly decreased throughout the day at $6 \mathrm{~h}$ (light on) and $12 \mathrm{~h}$ (light off) and then returned to the original expression level at $24 \mathrm{~h}$ (light on) (Fig. 2). In contrast, expression of PABP housekeeping gene was stable throughout the sampling period (ESM Fig. S1). The detection of TGF $\beta$ ss in aposymbiotic animals contrasts with our results in adult aposymbiotic $A$. pallida where expression was only detected in animals treated with Escherichia coli lipopolysaccharide (LPS), an immune elicitor (Detournay et al. 2012).

This contrast in expression pattern between adults and larvae deserves future investigation. It could indicate specific differences in the two study systems or could reflect differing immunity states between formerly symbiotic (bleached) adults and aposymbiotic larvae that engage immunity as a part of the selection process during onset of symbiosis. 
To explore involvement of TGF $\beta$ ss in the onset of symbiosis, aposymbiotic larvae of $F$. scutaria were incubated in anti-human TGF $\beta$ (anti-TGF $\beta$ ) before being inoculated with Symbiodinium sp. clade C1f cells. Colonization success decreased in a dose-dependent manner with increased anti-TGF $\beta$. This effect was measurable at $8 \mathrm{~h}$ (data not shown) and $20 \mathrm{~h}$ postcolonization when larvae were treated with doses as low as $0.01 \mu \mathrm{g} \mathrm{mL} \mathrm{L}^{-1}$ of anti-TGF $\beta$ (Fig. 3a). Isotype IgG controls (CO) were similar to no-treatment controls (NTC). Furthermore, percentage colonization in controls was similar to those in previous studies (Rodriguez-Lanetty et al. 2006). Although colonization decreased in a dose-dependent manner, we have no direct evidence that the anti-TGF $\beta$ used in this study specifically binds to TGF $\beta$ ss of $F$. scutaria. However, the use of cross-taxa antibodies has been employed in other systems (Padgett et al. 1993; Sampath et al. 1993; Franchini et al. 2006; Zoccola et al. 2009), and in our previous work with A. pallida, where we reported that inhibition of TGF $\beta$ and the subsequent elevation of NO production were only measurable during the symbiotic stage (Detournay et al. 2012).

Larvae inoculated with symbionts and incubated in anti-TGF $\beta$ exhibited an increase in NO release compared to both types of controls (Fig. 3b). Based on motility and larval integrity over time, no mortality or apparent decline in health was observed (ESM Fig. S4). These data suggest that larval controls (NTO, CO; Fig. 3) have functional TGF $\beta$ and tolerate the presence of colonizing symbionts whereas larvae with TGF $\beta$ blocked by presence of the antibody mount an immune response, as indicated by the release of NO, against the symbionts.

Colonization success by dinoflagellate symbionts of coral larvae with horizontal transmission is critical for surviving in nutrient-poor waters of coral reefs. This requires selective mechanisms whereby beneficial symbionts are recognized and maintained while inappropriate invaders are eliminated (Davy et al. 2012). We hypothesize that the TGF $\beta$ pathway plays an 
important role in the host immune system, aimed at tolerating "friend" while fighting "foe". How appropriate $\mathrm{C} 1 \mathrm{f}$ symbionts elicit a tolerogenic response in the presence of active TGF $\beta$ and the role that TGF $\beta$ ss might play in coral stress and bleaching are topics for future investigation.

\section{Acknowledgements}

We thank Jennifer Matthews, Ashley Sproles, Mary Hagedorn, Virginia L. Carter, and Ruth Gates for providing assistance in the field, equipment, and laboratory space. This is Hawaii Institute of Marine Biology contribution \#1476. This work has been supported by National Science Foundation Grants to VMW (IOB0542452 and IOB0919073). The 2014 field trip was financed by crowdfunding support to the Coral Guardian NGO foundation. We thank Eric Henry and Eric Rottinger for their help on the redaction as well as Benoit Miel-Istria, Sandrine

Convertino, Marie-Christine Rocci, Cristiana Bontemps and Mariella Coste.

\section{References}

Ainsworth TD, Heron SF, Ortiz JC, Mumby PJ, Grech A, Ogawa D, Eakin CM, Leggat W (2016) Climate change disables coral bleaching protection on the Great Barrier Reef. Science 352:338-342

Bogdan C, Nathan C (1993) Modulation of macrophage function by transforming growth factor beta, interleukin-4, and interleukin-10. Ann N Y Acad Sci 685:713-739

Buckley KM, Rast JP (2012) Dynamic evolution of toll-like receptor multigene families in echinoderms. Front Immunol 3:136

Davy SK, Allemand D, Weis VM (2012) Cell biology of cnidarian-dinoflagellate symbiosis. Microbiol Mol Biol Rev 76:229-261

Detournay O, Schnitzler CE, Poole A, Weis VM (2012) Regulation of cnidarian-dinoflagellate mutualisms: evidence that activation of a host TGFbeta innate immune pathway promotes tolerance of the symbiont. Dev Comp Immunol 38:525-537

Douglas AE (2003) Coral bleaching - how and why? Mar Pollut Bull 46:385-392

Franchini A, Malagoli D, Ottaviani E (2006) Cytokines and invertebrates: TGF-beta and PDGF. Curr Pharm Des 12:3025-3031

Fuess LE, Pinzomicronn CJ, Weil E, Mydlarz LD (2016) Associations between transcriptional changes and protein phenotypes provide insights into immune regulation in corals. Dev Comp Immunol 62:17-28 
Hamada M, Shoguchi E, Shinzato C, Kawashima T, Miller DJ, Satoh N (2013) The complex NOD-like receptor repertoire of the coral Acropora digitifera includes novel domain combinations. Mol Biol Evol 30:167-176

Herpin A, Lelong C, Becker T, Rosa FM, Favrel P, Cunningham C (2005) Structural and functional evidences for a type 1 TGF-beta sensu stricto receptor in the lophotrochozoan Crassostrea gigas suggest conserved molecular mechanisms controlling mesodermal patterning across bilateria. Mech Dev 122:695-705

Hughes TP, Kerry JT, Álvarez-Noriega M, Álvarez-Romero JG, Anderson KD, Baird AH, Babcock RC, Beger M, Bellwood DR, Berkelmans R, Bridge TC, Butler IR, Byrne M, Cantin NE, Comeau S, Connolly SR, Cumming GS, Dalton SJ, Diaz-Pulido G, Eakin CM, Figueira WF, Gilmour JP, Harrison HB, Heron SF, Hoey AS, Hobbs J-PA, Hoogenboom MO, Kennedy EV, Kuo C, Lough JM, Lowe RJ, Liu G, McCulloch MT, Malcolm HA, McWilliam MJ, Pandolfi JM, Pears RJ, Pratchett MS, Schoepf V, Simpson T, Skirving WJ, Sommer B, Torda G, Wachenfeld DR, Willis BL, Wilson SK (2017) Global warming and recurrent mass bleaching of corals. Nature 543:373-377

Karako-Lampert S, Zoccola D, Salmon-Divon M, Katzenellenbogen M, Tambutte S, Bertucci A, Hoegh-Guldberg O, Deleury E, Allemand D, Levy O (2014) Transcriptome analysis of the scleractinian coral Stylophora pistillata. PLoS One 9:e88615

Kitchen SA, Crowder CM, Poole AZ, Weis VM, Meyer E (2015) De novo assembly and characterization of four anthozoan (Phylum Cnidaria) transcriptomes. G3 (Bethesda) 5:2441-2452

Massague J (1998) TGF-beta signal transduction. Annu Rev Biochem 67:753-791

McFall-Ngai M (2008) Are biologists in 'future shock'? Symbiosis integrates biology across domains. Nat Rev Microbiol 6:789-792

Messier-Solek C, Buckley KM, Rast JP (2010) Highly diversified innate receptor systems and new forms of animal immunity. Semin Immunol 22:39-47

Miller DJ, Hemmrich G, Ball EE, Hayward DC, Khalturin K, Funayama N, Agata K, Bosch TC (2007) The innate immune repertoire in cnidaria — ancestral complexity and stochastic gene loss. Genome Biol 8:R59

Muscatine L, Falkowski P, Porter J, Dubinsky Z (1984) Fate of photosynthetic fixed carbon in light-adapted and shade-adapted colonies of the symbiotic coral Stylophora pistillata. Proc R Soc Lond B Biol Sci 222:181-202

Normile D (2016) El Nino's warmth devastating reefs worldwide. Science 352:15-16

Padgett RW, Wozney JM, Gelbart WM (1993) Human BMP sequences can confer normal dorsal-ventral patterning in the Drosophila embryo. Proc Natl Acad Sci U S A 90:29052909

Pang K, Ryan JF, Baxevanis AD, Martindale MQ (2011) Evolution of the TGF-beta signaling pathway and its potential role in the ctenophore, Mnemiopsis leidyi. PLoS One 6:e24152

Rodriguez-Lanetty M, Krupp DA, Weis V (2004) Distinct ITS types of Symbiodinium in Clade C correlate with cnidarian/dinoflagellate specificity during onset of symbiosis. Mar Ecol Prog Ser 275:97-102

Rodriguez-Lanetty M, Phillips WS, Weis VM (2006) Transcriptome analysis of a cnidariandinoflagellate mutualism reveals complex modulation of host gene expression. BMC Genomics 7:23

Ruscetti F, Varesio L, Ochoa A, Ortaldo J (1993) Pleiotropic effects of transforming growth factor-beta on cells of the immune system. Ann N Y Acad Sci 685:488-500 
Sampath TK, Rashka KE, Doctor JS, Tucker RF, Hoffmann FM (1993) Drosophila transforming growth factor beta superfamily proteins induce endochondral bone formation in mammals. Proc Natl Acad Sci U S A 90:6004-6008

Samuel G, Miller D, Saint R (2001) Conservation of a DPP/BMP signaling pathway in the nonbilateral cnidarian Acropora millepora. Evol Dev 3:241-250

Schnitzler CE, Weis VM (2010) Coral larvae exhibit few measurable transcriptional changes during the onset of coral-dinoflagellate endosymbiosis. Mar Genomics 3:107-116

Schwarz JA, Krupp DA, Weis VM (1999) Late larval development and onset of symbiosis in the scleractinian coral Fungia scutaria. Biol Bull 196:70-79

Shinzato C, Shoguchi E, Kawashima T, Hamada M, Hisata K, Tanaka M, Fujie M, Fujiwara M, Koyanagi R, Ikuta T, Fujiyama A, Miller DJ, Satoh N (2011) Using the Acropora digitifera genome to understand coral responses to environmental change. Nature 476:320-323

Srivastava M, Simakov O, Chapman J, Fahey B, Gauthier ME, Mitros T, Richards GS, Conaco C, Dacre M, Hellsten U, Larroux C, Putnam NH, Stanke M, Adamska M, Darling A, Degnan SM, Oakley TH, Plachetzki DC, Zhai Y, Adamski M, Calcino A, Cummins SF, Goodstein DM, Harris C, Jackson DJ, Leys SP, Shu S, Woodcroft BJ, Vervoort M, Kosik KS, Manning G, Degnan BM, Rokhsar DS (2010) The Amphimedon queenslandica genome and the evolution of animal complexity. Nature 466:720-726

Weis VM (2008) Cellular mechanisms of cnidarian bleaching: stress causes the collapse of symbiosis. J Exp Biol 211:3059-3066

Yellowlees D, Rees TA, Leggat W (2008) Metabolic interactions between algal symbionts and invertebrate hosts. Plant Cell Environ 31:679-694

Zoccola D, Moya A, Beranger GE, Tambutte E, Allemand D, Carle GF, Tambutte S (2009) Specific expression of BMP2/4 ortholog in biomineralizing tissues of corals and action on mouse BMP receptor. Mar Biotechnol (NY) 11:260-269 


\section{Figure legends}

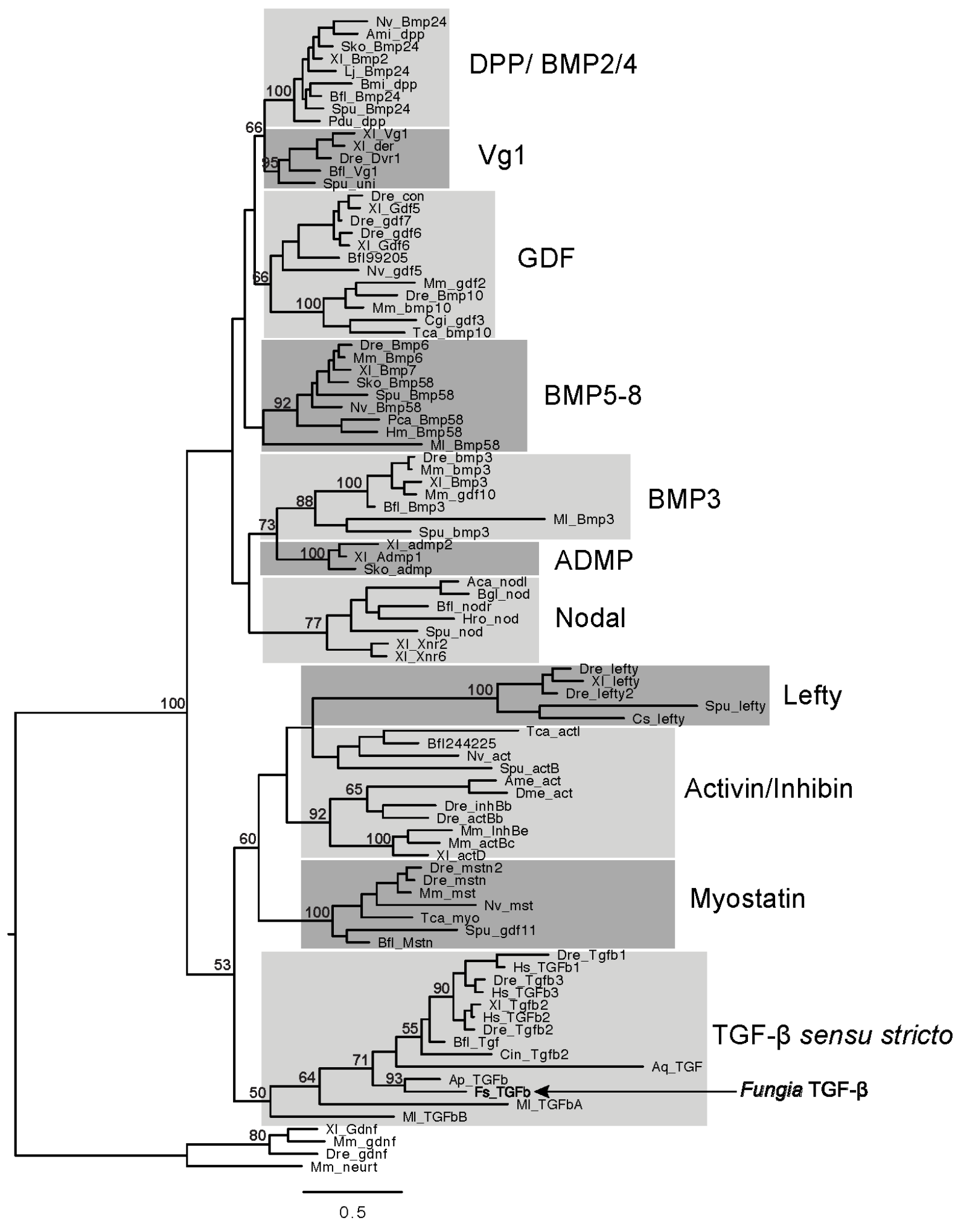


Fig. 1 A phylogenetic tree generated using Bayesian analysis of mature sequences of transforming growth factor beta (TGF $\beta$ ) family members, including Fungia scutaria TGF $\beta$ sensu stricto (FsTGF $\beta$ ss), highlighted with an arrow. Posterior probabilities are displayed at the nodes. Taxon abbreviations and sequence accession numbers are listed in the Electronic Supplementary Materials Table S2

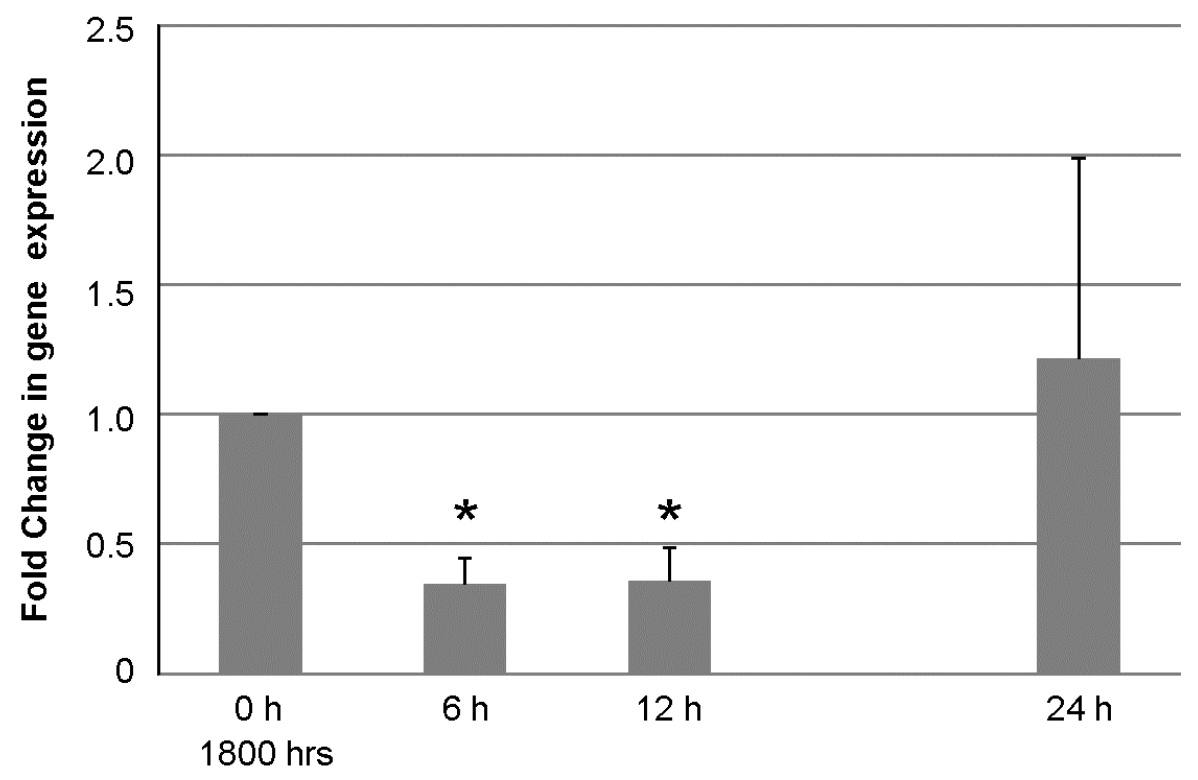

Fig. 2 Fungia scutaria TGF $\beta$ sensu stricto (FsTGF $\beta$ ss) expression in aposymbiotic $F$. scutaria larvae at four time points of the experiment $(0,6,12,24 \mathrm{~h})$ and relative to the gene expression at time $0 \mathrm{~h}(1800 \mathrm{hrs})$. Light was on at $0,6,24 \mathrm{~h}$ and off at $12 \mathrm{~h}$. Bars are fold change relative to aposymbiotic larvae at time $0 \pm \mathrm{SE}, \mathrm{n}=3$, t-test to control with $* \mathrm{p}<0.05$ 
a)

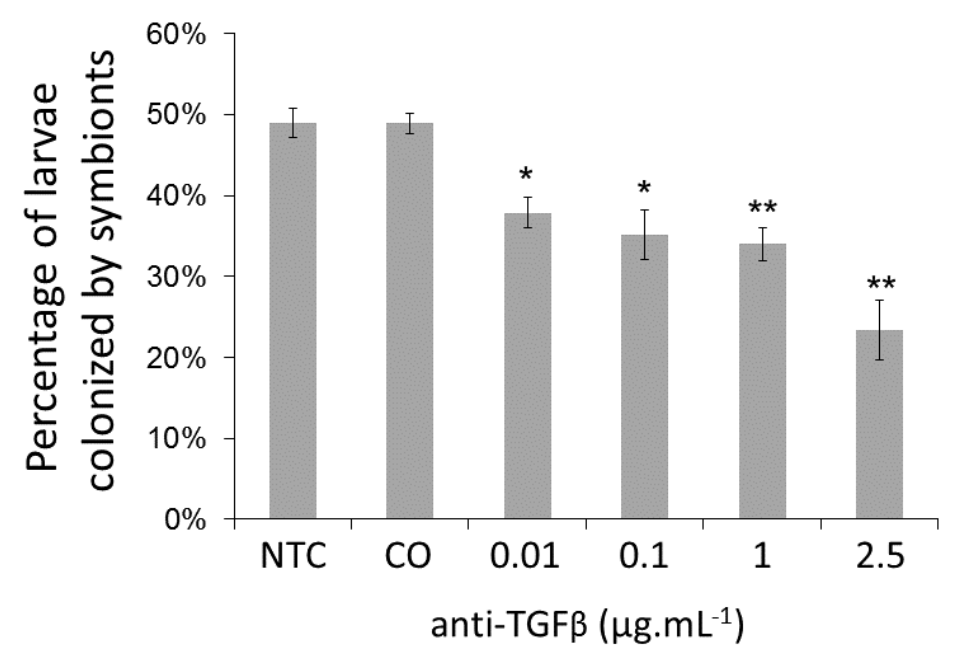

b)

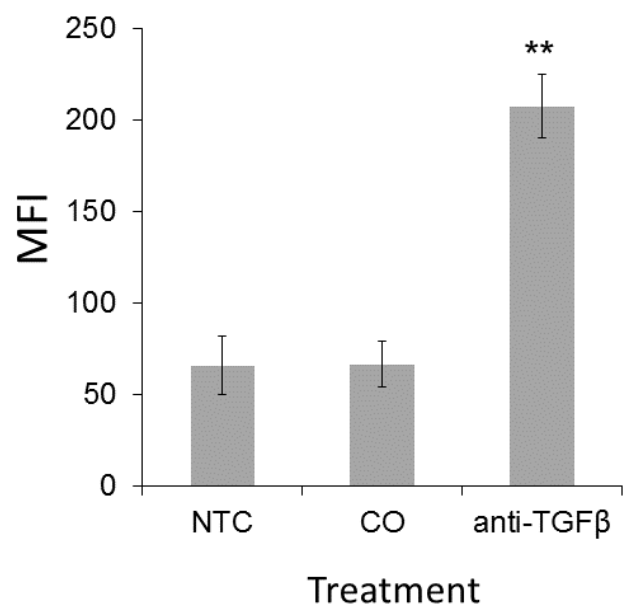

Fig. 3 a Percentage of larvae colonized by symbionts as a function of increasing concentrations of anti-human transforming growth factor beta (TGF $\beta$ ). Bars are percentage of total larval population that was colonized by symbiont (number of larvae counted $>100$ ) $\pm \mathrm{SE}, \mathrm{n}=4$, ANOVA post hoc Bonferroni to CO (isotype IgG control), ${ }^{*} \mathrm{p}<0.05$ and $* * \mathrm{p}<0.001$. NTC: no-treatment control. b Mean fluorescence intensity (MFI) of DAF-FM DA, a probe for NO, a proxy for an immune response in colonized larvae. Bars represent means (number of larvae counted $>10) \pm \mathrm{SE} ; \mathrm{n}=4$, t-test to CO (isotype IgG control) $* \mathrm{p}<0.05, * * \mathrm{p}<0.001$. NTC: notreatment control 